Article

\title{
Effect of Hydrophilicity of Activated Carbon Electrodes on Desalination Performance in Membrane Capacitive Deionization
}

\author{
Kyusik Jo ${ }^{1}$, Youngbin Baek ${ }^{2, *}$, Changha Lee ${ }^{1}$ and Jeyong Yoon ${ }^{1,3, *}$ \\ 1 School of Chemical and Biological Engineering and Institute of Chemical Processes (ICP), Seoul National \\ University, 1 Gwanak-ro, Gwanak-gu, Seoul 08826, Korea; dakkhoss@snu.ac.kr (K.J.); \\ leechangha@snu.ac.kr (C.L.) \\ 2 Department of Biotechnology, Sungshin Women's University, Seoul 01133, Korea \\ 3 Korea Environment Institute, 370 Sicheong-daero, Sejong-si 30147, Korea \\ * Correspondence: ybbaek@sungshin.ac.kr (Y.B.); jeyong@snu.ac.kr (J.Y.)
}

Received: 3 November 2019; Accepted: 21 November 2019; Published: 23 November 2019

check for updates

\begin{abstract}
Membrane capacitive deionization (MCDI) is a modification of capacitive deionization (CDI) using ion-exchange membranes (IEM) in front of the electrodes. Electrode properties, especially the specific surface area, are known to be strongly related with desalination performance in CDI, but the effects of other properties in MCDI are not fully understood. The objective of this study was to investigate the effect of hydrophilicity in activated carbon electrodes on desalination performance in MCDI. Two types of activated carbon (P60 and YS-2) whose specific surface areas were similar were used as electrode materials, but they had different hydrophilicity (i.e., P60 was originally hydrophobic and YS-2 was relatively hydrophilic due to its nitrogen-containing surface chemistry). These hydrophilic electrodes (either the electrode itself or modified with polydopamine (PDA)) led to an increase in the salt adsorption capacity (SAC) in MCDI because they facilitated the access of both ions and water molecules into the electrode pores. In particular, the SAC of the P60 electrode displayed a large increase to almost reach that of the YS-2 electrode due to the improved hydrophilicity with PDA modification and the insignificant effects of PDA modification on an already hydrophilic YS-2 electrode. Additionally, PDA-modified IEM in MCDI reduced the SAC as a result of the additional insulating PDA layer with little changes in hydrophilicity.
\end{abstract}

Keywords: membrane capacitive deionization (MCDI); desalination; activated carbon; hydrophilicity; polydopamine

\section{Introduction}

Capacitive deionization (CDI) is a novel desalination technology that is integrated with energy storage technology (i.e., electric double layer capacitor). Since the electric double layer has an important role in CDI, desalination performance is strongly affected by the physical and chemical properties of the electrode materials. Generally, carbon materials are used as electrode materials in CDI because of their excellent electrical properties and low cost. Activated carbon (AC) is the most common carbon material [1-6], and other variants such as carbon nanotubes [7-9], graphene [10-13], and templated carbon [14-17] have also been employed in CDI technology for desalination.

Membrane capacitive deionization (MCDI) is a modification of CDI with an additional ion exchange membrane (IEM) equipped onto each electrode (an anion exchange and a cation exchange membrane). Adding IEMs in CDI has improved desalination performance. Lee et al. [18] reported that MCDI increased the ion removal rate by approximately $20 \%$ when using an activated carbon cloth as 
an electrode and a commercial IEM. Li et al. [19] demonstrated an improved salt removal efficiency of approximately 37\% in MCDI when using graphite-based electrodes incorporated with single-walled carbon nanotubes and IEM. An additional 5\% salt removal efficiency was achieved by applying higher voltages of up to $1.6 \mathrm{~V}$. Placing the IEM in front of the electrode also significantly increased the charge efficiency of the salt ion adsorption/desorption [20,21] due to the inhibition of co-ion repulsion affected by the IEM acting as a charge barrier and the additional ion storage in the interparticle spaces of the electrode [22-24].

Electrode properties are strongly correlated with the desalination performance in CDI and MCDI [25]. It is well known that the specific surface area of the electrode is linearly correlated with the salt adsorption capacity (SAC) [1]. Besides the specific surface area, which is a physical property, hydrophilicity is also considered to improve the desalination performance in CDI because a hydrophilic electrode surface allows the ions to be transported more easily within the porous electrode. Although the electrode modification in CDI has been studied in the literature [26-28], studies focusing on the hydrophilicity of electrode have been limitedly reported. For example, Kim et al. [29] reported approximately twice the desalination performance using an $\mathrm{AC}$ electrode modified with $\mathrm{TiO}_{2}$ using the sol-gel spray method. The $\mathrm{TiO}_{2}$-modified electrode significantly increased the hydrophilicity from $132^{\circ}$ to $15^{\circ}$ of contact angle. Xie et al. [30] exhibited that polydopamine (PDA)-modified AC reduced the contact angle from $120^{\circ}$ to $65^{\circ}$, resulting in more than twice the desalination performance in CDI. Despite these previous works on the hydrophilic modification of electrodes in CDI [29,30], there is limitedly published data for the effects of hydrophilic electrodes on the desalination performance in the presence of IEM, that is MCDI.

The objective of this study was to investigate the effect of hydrophilicity in AC electrodes on the maximum capacity utilization in MCDI. Two ACs (hydrophobic P60 and hydrophilic YS-2) were chosen as electrode materials and compared with each other as they have similar specific surface areas but different hydrophilicities. SACs were obtained from single-pass desalination experiments in MCDI. Furthermore, the AC electrodes and/or IEMs were modified with PDA to enhance their hydrophilicity. The results provide the relationship between the electrode hydrophilicity and the desalination performance in MCDI.

\section{Materials and Methods}

\subsection{Electrode Fabrication}

The electrodes were fabricated with two types of ACs by the roll pressing method [1]: P60 (Kuraray Chemical, Osaka, Japan) and YS-2 (Japan Enviro Chemicals, Osaka, Japan). Carbon dough was prepared by mixing AC powder, carbon black (Super P, Timcal, Osaka, Switzerland), and polymer binder (PTFE, Sigma Aldrich, St. Louis, MI, USA), by 86:7:7 weight percentage ratio, respectively. The well-mixed dough was pressed to approximately $300 \mu \mathrm{m}$ thickness using a roll pressing machine. The fabricated carbon electrode was dried in a vacuum oven at $120^{\circ} \mathrm{C}$ for $12 \mathrm{~h}$ followed by cutting the electrodes in a round shape ( $20 \mathrm{~mm}$ in diameter) with a small hole (4 $\mathrm{mm}$ in diameter) at the center of the electrode.

\subsection{Polydopamine Modification}

The electrodes and IEM were modified with PDA to increase the surface hydrophilicity [30-32]. For crafting the PDA solution, $2 \mathrm{~g} \mathrm{~L}^{-1}$ of dopamine hydrochloride (Sigma-Aldrich, St. Louis, MI, USA) was dissolved into $15 \mathrm{mM}$ Tris buffer solution at pH 8.8 (Sigma-Aldrich, St. Louis, MI, USA). As dopamine is self-polymerized in an alkaline condition, the dopamine solution was immediately poured onto either an electrode/IEM in a Petri dish. The dopamine solution containing the electrode/IEM was gently mixed on a rocker platform (RK-1D, Daihan Scientific, Wonju-si, Korea) for $1 \mathrm{~h}$. The PDA-modified electrodes/IEMs were washed thoroughly with DI water (deionized water) to remove any residual PDA solution. 


\subsection{Electrode Characterization}

The physical properties of the two ACs, including the total specific surface area (SSA) and the pore volume, were measured by $\mathrm{N}_{2}$ adsorption isotherms (ASAP 2020, Micromeritics, Norcross, GA, USA) at $-196^{\circ} \mathrm{C}$ temperature after degassing them at $110^{\circ} \mathrm{C}$ for $2 \mathrm{~h}$ and the isotherm data were calculated with the Brunauer-Emmett-Teller (BET) equation. Fourier-transform infrared spectroscopy (FT-IR, Nicolet 6700, Thermo Scientific, Waltham, MA, USA) was conducted to investigate the surface functional groups of both the ACs (P60 and YS-2), which were pelletized for measuring their IR spectra by mixing the samples with $\mathrm{KBr}$ salts. The spectra were scanned in a range of $4000 \sim 400 \mathrm{~cm}^{-1}$. Hydrophilicities of the electrodes were measured using a contact angle analyzer (DSA 100, KRÜSS, Hamburg, Germany) with the sessile drop method, in which a $3 \mu \mathrm{L}$ of DI water droplet was deposited onto the electrode and/or membrane surface at a minimum of five points and changes in contact angle were tracked for $1 \mathrm{~min}$. The samples were dried for a minimum of $6 \mathrm{~h}$ in a vacuum oven at $70^{\circ} \mathrm{C}$. X-ray photoelectron spectroscopy (XPS, SIGMA PROBE, ThermoFisher Scientific, Waltham, MA, USA) was conducted to determine the PDA coating quality. XPS spectra were collected using a monochromatic $\mathrm{Al} \mathrm{K} \alpha$ from 0 to $1200 \mathrm{eV}$.

\subsection{Desalination Experiments}

The MCDI system used to examine the desalination performance is described in Scheme 1. Each electrode consisted of graphite as the current collector, an AC electrode, and an IEM. An anion-exchange membrane (AMV, Selemion, Tokyo, Japan) and cation-exchange membrane (CMV, Selemion, Tokyo, Japan) were placed on the anode and cathode, respectively. The pair of electrodes were separated by a nylon spacer with a thickness of $110 \mu \mathrm{m}$. A feed water (10 $\mathrm{mM} \mathrm{NaCl}$ solution) was supplied to the cell using a peristaltic pump (Minipuls 3, Gilson, Middleton, WI, USA). The treated solution directly flowed through a conductivity meter (3573-10C, Horiba, Kyoto, Japan) and was subsequently discarded (i.e., single-pass mode). CDI experiments were also performed with the same configuration as used in MCDI except for the presence of the IEM. Voltage was applied using a battery cycler (WBCS3000, WonATech, Seoul, Korea) for $10 \mathrm{~min}$ each at $1.2 \mathrm{~V}$ in the charging step and $0 \mathrm{~V}$ in the discharging step. Data were obtained from the third cycle and an average value was calculated from a minimum of three operations for reproducibility.

The MCDI desalination performance was evaluated in terms of SAC and the average salt adsorption rate (ASAR). The SAC was calculated by integrating the decreased conductivity, as given in Equation (1) [33]:

$$
S A C\left(m g g^{-1}\right)=\frac{Q \cdot M_{w} \cdot \int\left(C_{\text {in }}-C_{\text {out }}\right) d t}{m}
$$

where $\mathrm{C}_{\text {in }}$ and $\mathrm{C}_{\text {out }}$ are the influent and effluent concentrations of $\mathrm{NaCl}(\mathrm{mM}) ; \mathrm{Q}$ is the flow rate ( $\mathrm{L}$ $\left.\mathrm{min}^{-1}\right)$; $\mathrm{MW}$ is the molecular weight of $\mathrm{NaCl}\left(58.443 \mathrm{~g} \mathrm{~mol}^{-1}\right)$, and $\mathrm{m}$ is the electrode weight $(\mathrm{g})$. The average values of SAC were statistically analyzed by $\mathrm{t}$-test.

ASAR was obtained using Equation (2) [34]:

$$
\operatorname{ASAR}\left(m g g^{-1} s^{-1}\right)=\frac{Q \cdot M_{W} \cdot \int\left(C_{\text {in }}-C_{\text {out }}\right) d t}{m \int d t}
$$

CDI was conducted additionally under constant current charging operations to evaluate the capacity and kinetics of the electrodes using a CDI Ragone plot. Data for MCDI were obtained with different applied currents (1-3.5 $\mathrm{mA} \mathrm{cm}^{-2}$ ) with a step of $0.5 \mathrm{~mA} \mathrm{~cm}{ }^{-2}$ during the charging step and $0 \mathrm{~V}$ was applied for discharging. More details are described in the literature [35]. 


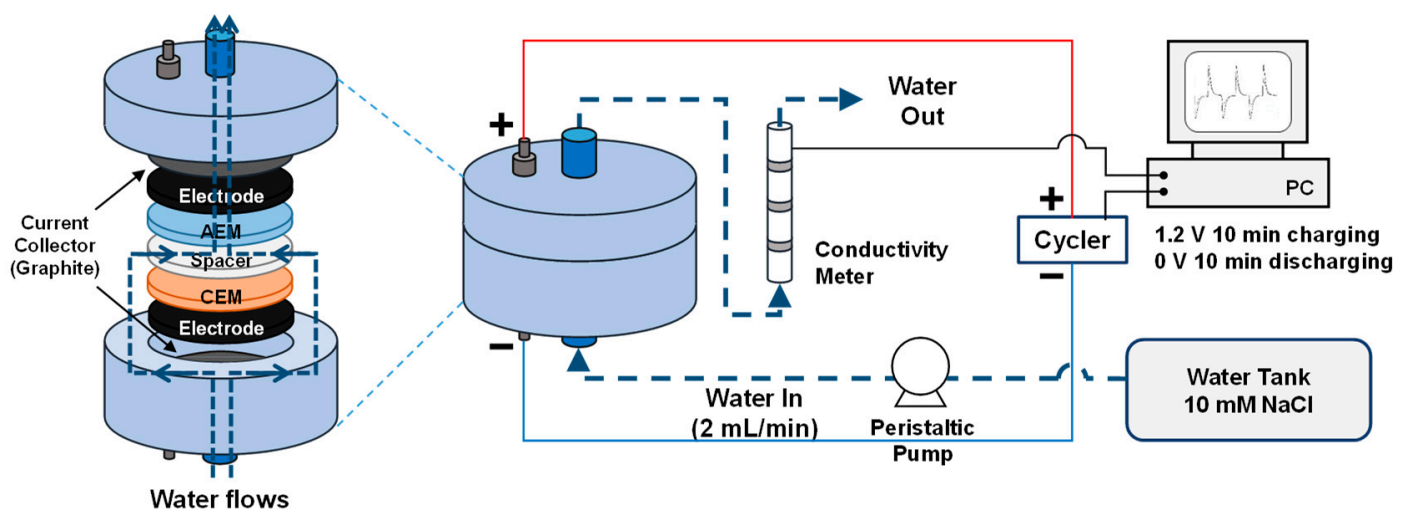

Scheme 1. A schematic diagram of membrane capacitive deionization (MCDI) system. Ion-exchange membranes were equipped in front of the electrode. Then, $10 \mathrm{mM}$ of $\mathrm{NaCl}$ solution was supplied to the MCDI cell at $2 \mathrm{~mL} \mathrm{~min}^{-1}$ of flow rate. Treated solution flowed by the conductivity meter and was discarded subsequently. The applied voltage was $1.2 \mathrm{~V}$ at the charging step and $0 \mathrm{~V}$ at the discharging step for $10 \mathrm{~min}$ each.

\section{Results}

\subsection{Characteristics of Activated Carbon and Electrode}

Table 1 summarizes the physical properties of P60 and YS-2 (for both powder and electrode forms) such as total BET SSA and total pore volume. The total BET SSAs for P60 and YS-2 were similar, being 1621 and $1554 \mathrm{~m}^{2} \mathrm{~g}^{-1}$, respectively, while they had a similar pore volume of $0.8 \mathrm{~cm}^{3} \mathrm{~g}^{-1}$. After the electrode fabrication, their physical properties reduced at a similar rate of approximately $20 \%$ in both electrodes. The decreased surface area and pore volume can be explained by a probable blockage of $\mathrm{AC}$ pores by the conductive material and binder.

Table 1. Physical properties of P60 and YS-2 as powder and electrode.

\begin{tabular}{cccc}
\hline Type & Activated Carbon & Total BET Specific Surface Area $\left(\mathbf{m}^{\mathbf{2}} \mathbf{g}^{-\mathbf{1}}\right)$ & Total Pore Volume $\left(\mathbf{c m}^{\mathbf{3}} \mathbf{g}^{-\mathbf{1}}\right)$ \\
\hline \multirow{2}{*}{ Powder } & P60 & 1621 & 0.82 \\
& YS-2 & 1554 & 0.80 \\
\hline \multirow{2}{*}{ Electrode } & P60 & 1256 & 0.65 \\
& YS-2 & 1217 & 0.63 \\
\hline
\end{tabular}

BET-Brunauer-Emmett-Teller.

Although both ACs had similar physical properties, the wettability of the two electrodes ('P60 electrode' and 'YS-2 electrode') appeared to have different behaviors, as shown in Figure 1a. After $1 \mathrm{~min}$, the contact angle value of the YS-2 electrode displayed a large decrease from $118^{\circ}$ to $0^{\circ}$, while that of the P60 electrode slightly decreased from $130^{\circ}$ to $115^{\circ}$. The large decrease in the contact angle on the YS-2 electrode indicates a good wettability. To further analyze the excellent wettability of the YS-2 electrode, FT-IR analysis was conducted as shown in Figure 1b. The FT-IR spectra of both the electrodes showed typical ACs: C-O at $900-1300 \mathrm{~cm}^{-1}$; $\mathrm{C}-\mathrm{H}$ at 1430,2850 , and $2917 \mathrm{~cm}^{-1}$; C=O at 1093 and $1631 \mathrm{~cm}^{-1}$; and $-\mathrm{OH}$ at $3000-3700 \mathrm{~cm}^{-1}$ [36,37], except for an additional peak for the YS-2 electrode at 1570 and $1190 \mathrm{~cm}^{-1}$, which corresponds to $\mathrm{C}=\mathrm{N}$ and $\mathrm{C}-\mathrm{N}$, respectively. It is known that there is a possible addition of an $\mathrm{N}$-terminated functional group when activated carbons are treated with gaseous ammonia [36]. This property of the YS-2 electrode resulted in a faster adsorption of water molecules as well as dissolved ions into the electrode [38]. 
(a)
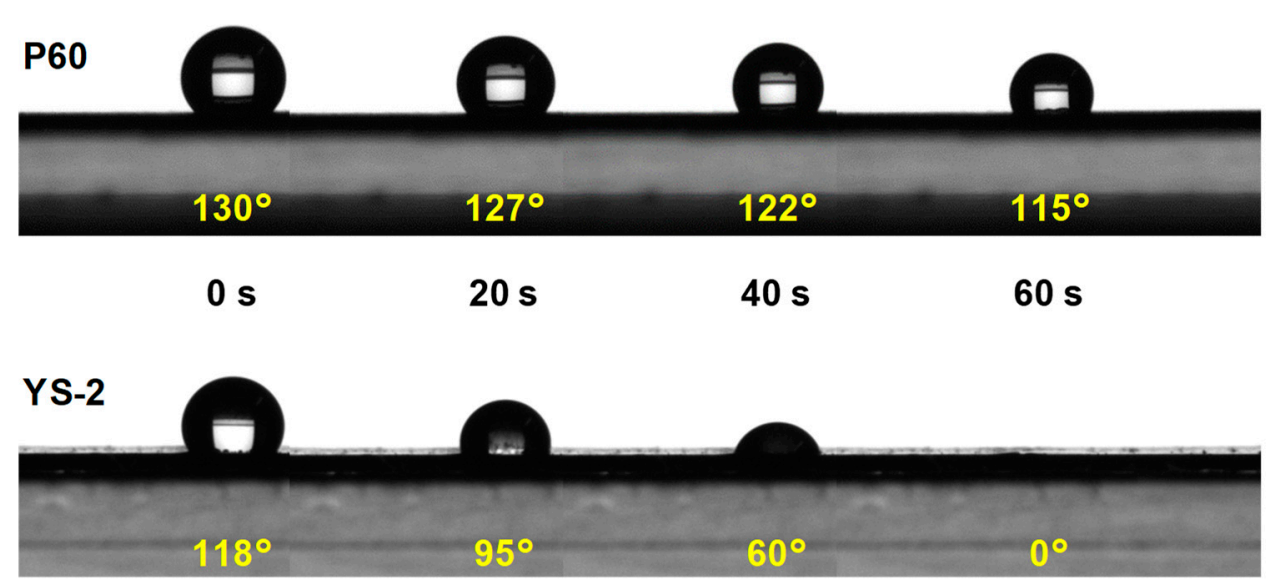

(b)

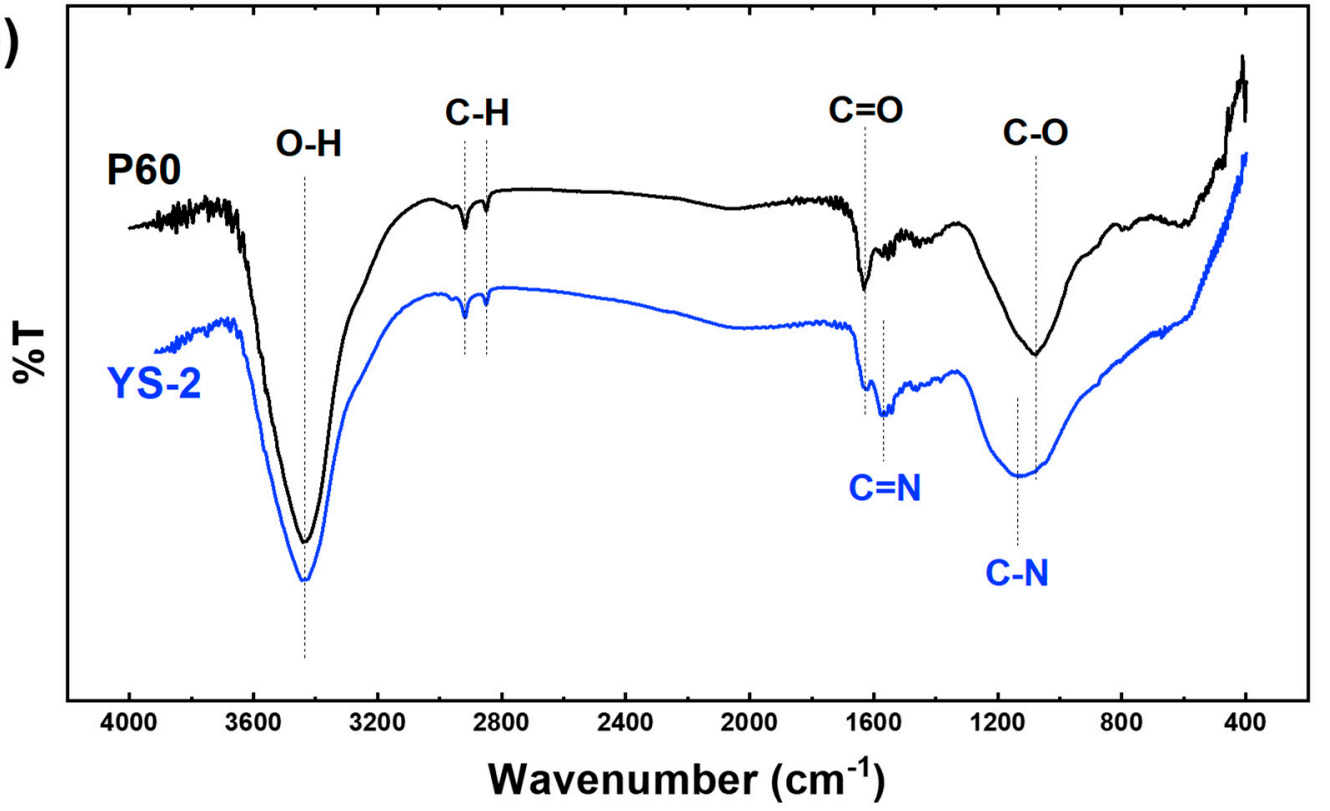

Figure 1. (a) Contact angle changes of two electrodes fabricated with P60 and YS-2 as function of time and (b) FT-IR spectra of P60 and YS-2.

\subsection{Effects of Electrode Hydrophilicity on MCDI Performance}

Figure 2 shows the MCDI performance using P60 and YS-2 electrodes in terms of (a) normalized conductivity profile; (b) specific current profile; (c) cumulative SAC; and (d) ASAR. The black solid line and blue dashed line represent the data obtained with the P60 electrode and YS-2 electrode, respectively. As seen in Figure 2a, the normalized conductivity displayed a lower and broader drop in the case of the YS-2 electrode during the charging step in comparison to the P60 electrode. Specific currents shown in Figure $2 \mathrm{~b}$ also appear higher for the YS-2 electrode at the beginning of the charging step. Figure $2 \mathrm{a}, \mathrm{b}$ in the MCDI indicates that more ions were adsorbed onto the surface of the YS-2 electrode in the initial few minutes of the charging step. Figure 2c,d shows the cumulative SAC and ASAR, calculated by Equations (1) and (2), respectively. In both the figures, the blue dashed line (YS-2 electrode) was positioned higher than the black solid line (P60 electrode), which means that faster and higher salt adsorption was achieved on the YS-2 electrode. It could be inferred that the accessible surface area for ions on the hydrophilic YS-2 electrode was larger than on the hydrophobic P60 electrode due to an easier approach for the water molecules into the micropores. 
(a)
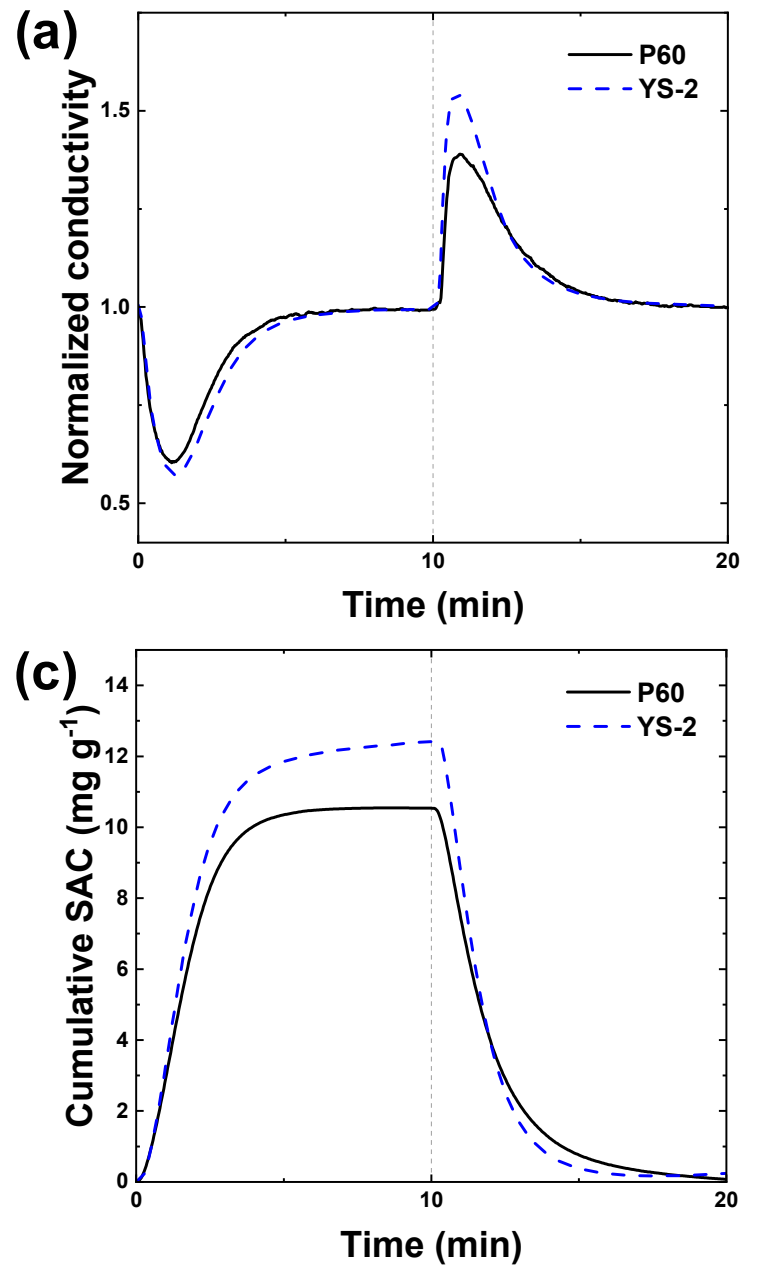
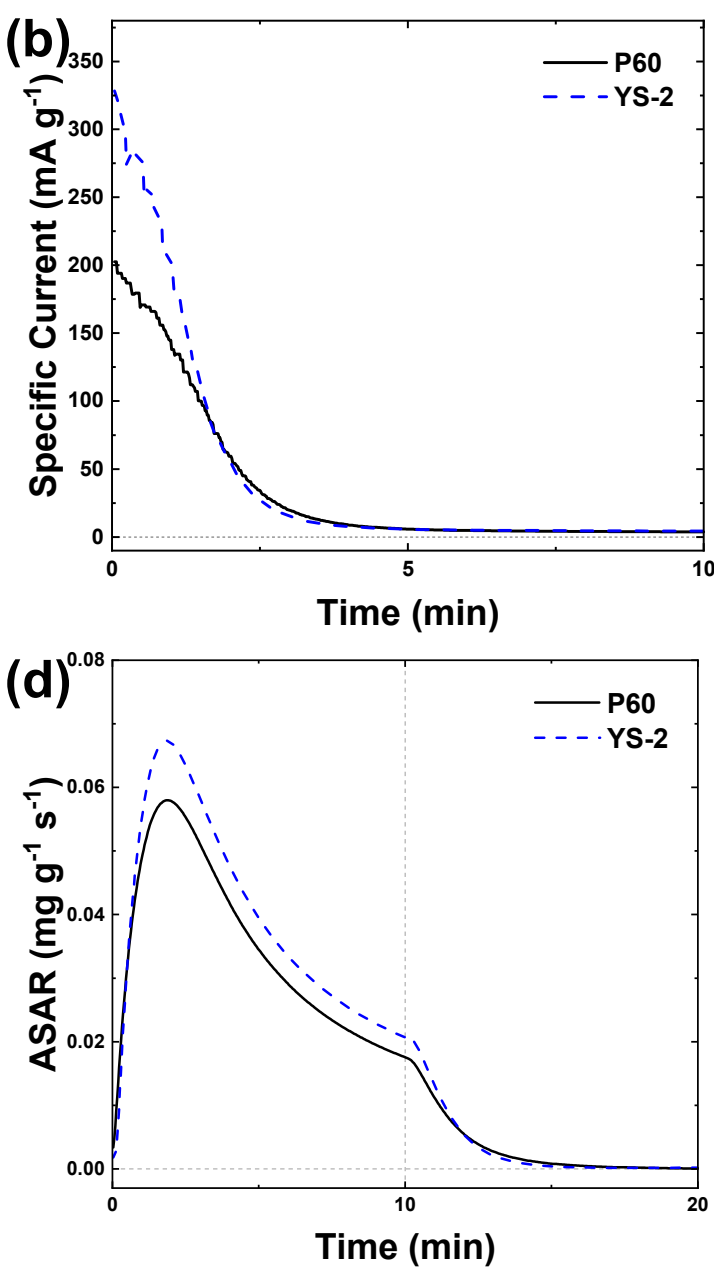

Figure 2. Membrane capacitive deionization (MCDI) performances using P60 and YS-2 electrodes; (a) normalized conductivity profiles; (b) specific current $\left(\mathrm{mA} \mathrm{g}^{-1}\right)$; (c) cumulative salt adsorption capacity $\left(\mathrm{SAC}, \mathrm{mg} \mathrm{g}^{-1}\right.$ ); and (d) average salt adsorption rate (ASAR, $\mathrm{mg} \mathrm{g}^{-1} \mathrm{~s}^{-1}$ ) with time of P60 electrode (black) and YS-2 electrode (blue). All graphs were the result of the nearest set to the average value.

Table 2 displays the SACs of the P60 electrode and the YS-2 electrode in the MCDI calculated from the normalized conductivity changes. The SAC of the YS-2 electrode was larger $\left(13.0 \pm 0.9 \mathrm{mg} \mathrm{g}^{-1}\right)$ than that of the P60 electrode $\left(11.1 \pm 1.2 \mathrm{mg} \mathrm{g}^{-1}\right)$. Note that the $\mathrm{p}$-value for those SACs was approximately 0.01 , indicating that those SACs are statistically different [39]. As the physical properties of both the electrodes were similar, the larger SAC of the YS-2 electrode reflects the effect of hydrophilicity on the desalination performance. Notably, similar behavior was observed in the CDI; the SAC of the YS-2 electrode was $10.1 \pm 0.7 \mathrm{mg} \mathrm{g}^{-1}$ and that of the P60 electrode was $9.5 \pm 0.8 \mathrm{mg} \mathrm{g}^{-1}$, as shown in Supplementary Figure S1. Previous studies on the improved CDI performance using hydrophilic electrodes have demonstrated that a hydrophilic surface resulted in enhanced ion transportation $[30,40]$ and ion accessibility to the pores [41], and better interaction between the carbon surface and the electrolytes [42-44]. The results from Figure 2 and Table 2 demonstrate the effect of hydrophilicity on MCDI when the physical properties of the electrodes were similar.

Table 2. Salt adsorption capacity (SAC) of P60 electrode and YS-2 electrode in MCDI.

\begin{tabular}{cc}
\hline Activated Carbon Electrode & Salt Adsorption Capacity $\left.\mathbf{~ m g ~ g ~}^{\mathbf{- 1}}\right)$ \\
\hline P60 & $11.1 \pm 1.2$ \\
YS-2 & $13.0 \pm 0.9$ \\
\hline
\end{tabular}




\subsection{Enhancement of Hydrophilicity by Polydopamine Modification}

Polydopamine surface modification was performed to further evaluate the effects of hydrophilicity on the electrode. Figure 3 shows the changes in surface hydrophilicity and elemental composition of PDA-modified electrodes. After PDA modification, the initial contact angles of both electrodes were significantly reduced (i.e., from $130^{\circ}$ to $50^{\circ}$ for the P60 electrode and from $118^{\circ}$ to $41^{\circ}$ for the YS-2 electrode) and the water droplets were almost completely absorbed into both the electrodes after $3 \mathrm{~s}$ Figure $3 a, b$. These changes in contact angles indicate that both electrodes had higher hydrophilicity compared to pristine electrodes (i.e., $130^{\circ}$ for P60 electrode and $118^{\circ}$ for YS-2 electrode). Notably, the changes in the hydrophilicity of IEMs after PDA modification were negligible (Supplementary Figure S2). The results of IEM modifications are discussed later.

Figure 3c,d represent the XPS spectra of the P60 and YS-2 electrodes in pristine (black line) and PDA-modified (red line) forms. Three major peaks-C1s, O1s, and F1s-were commonly observed in the spectra of the pristine electrode, indicating carbons, oxygenated functional groups, and fluorine from a PTFE binder, respectively. After the PDA modification, an additional N1s peak, an increase in the O1s peak, and a decrease in the $\mathrm{C} 1 \mathrm{~s}$ peak were observed. These changes were commonly attributed to the presence of polydopamine on the electrode surface because dopamine includes both hydroxyl and amine groups [30].

(a)
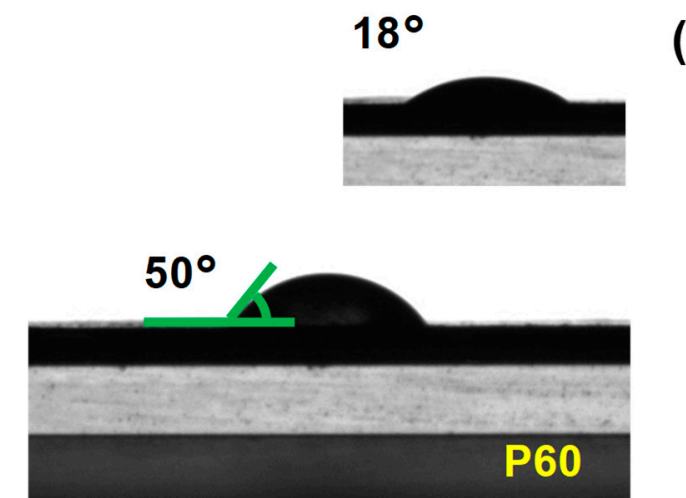

(c)

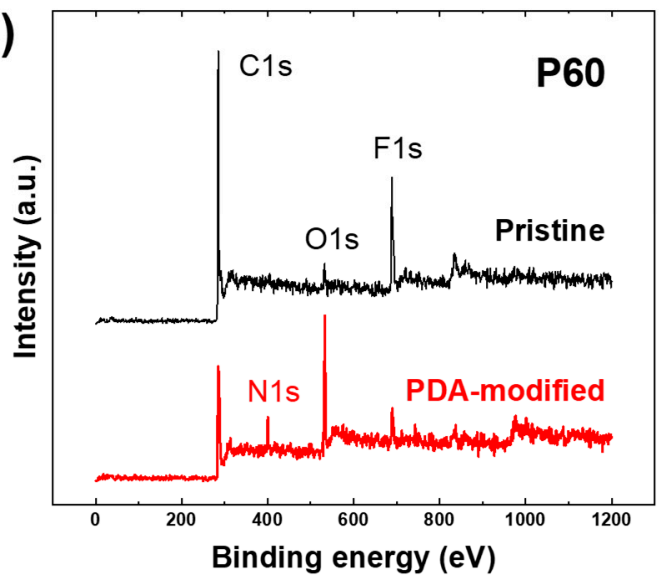

(b)
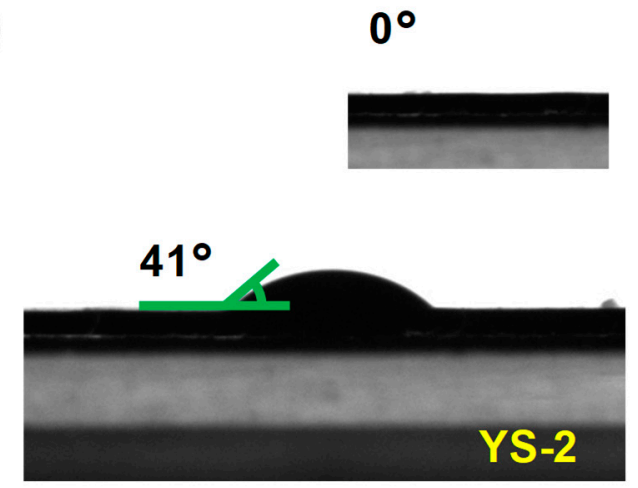

(d)

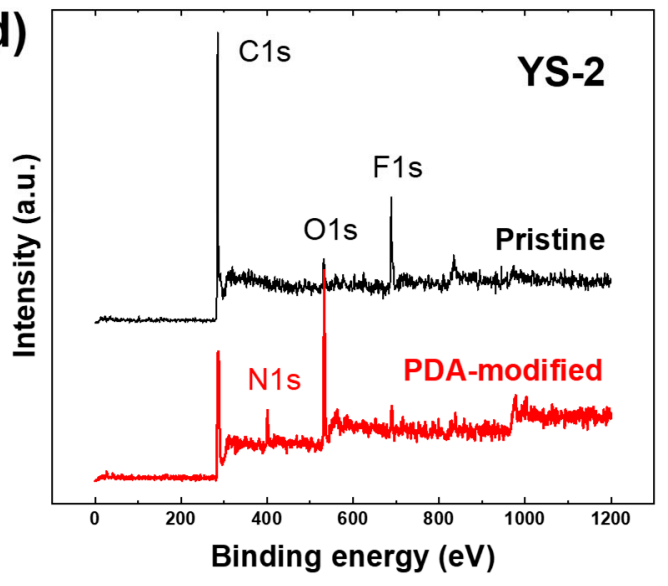

Figure 3. Contact angle images of (a) P60 electrode and (b) YS-2 electrode after polydopamine (PDA) modification (upper-right images were taken after 3 s) and XPS spectra of (c) P60 and (d) YS-2 as pristine (black) and PDA-modified electrodes (red).

Figure 4 shows the relative SAC in MCDI for three combinations of the electrode and IEM: PDA-modified electrode and pristine IEM $\left(\mathrm{E}_{\mathrm{PDA}}+\mathrm{IEM}_{\mathrm{P}}\right)$, pristine electrode and PDA-modified IEM $\left(E_{P}+I_{P M_{P D A}}\right)$, and PDA-modified electrode and IEM (EPDA + IEMPDA $)$. The SACs were summarized in Table 3. Relative SAC was calculated from these SACs by subtracting from and dividing by the 
SAC of the MCDI (refer to Table 2) with a pristine electrode and IEM. As shown in Figure 4, the PDA-modified P60 electrode significantly increased the SAC by approximately $20 \%$, while the changes in SAC using the YS-2 electrode before/after PDA modification were insignificant. The probable explanation is that the PDA modification of the hydrophobic P60 electrode had a large effect on the desalination performance, while the YS-2 electrode with already good wettability did not get affected by additional hydrophilic modification.

A similar large change in the SAC in case of the P60 electrode compared to the YS-2 electrode was observed in the CDI configuration without IEM, as shown in Supplementary Figure S3. In CDI, the observed SACs were $10.2 \pm 1.0$ and $10.2 \pm 1.5 \mathrm{mg} \mathrm{g}^{-1}$ for the PDA-modified P60 and YS-2 electrodes, respectively, with 0.7 and $0.1 \mathrm{mg} \mathrm{g}^{-1}$ improvement. This improvement is consistent with a previous study showing a higher desalination performance achieved by decreasing the contact angle of the modified electrodes [35,36]. As can be seen in Figure 4 and Supplementary Figures S1 and S3, PDA modification improved the SAC of P60 electrodes to a level almost similar to the SAC of PDA-modified YS-2 electrodes. This result with the PDA-modified electrodes in both the MCDI and CDI suggests that the SAC of approximately $13-14 \mathrm{mg} \mathrm{g}^{-1}$ for MCDI (10 $\mathrm{mg} \mathrm{g}^{-1}$ for CDI) may be the maximum achievable value because both the electrodes became sufficiently hydrophilic with a good wettability. It is important to note that the total BET SSA of the AC was reduced by approximately $10 \%$ after PDA modification ( $851 \mathrm{~m}^{2} \mathrm{~g}^{-1}$ for P60 and $864 \mathrm{~m}^{2} \mathrm{~g}^{-1}$ for YS-2) in consideration, the increase in electrode mass was about $20 \%$. Therefore, the higher SAC, regardless of the reduced SSA, means that a more hydrophilic electrode promotes the access of both ions and electrolytes into the electrode pores [38].

However, the SAC decreased by approximately $8 \%$ when the IEM was modified with PDA in both the types of electrodes. This decrease in SAC with PDA-modified IEM may be due to the unchanged hydrophilicity (Supplementary Figure S2) and the hindered ion transportation through the PDA, which covered the IEM and possibly acted as an insulator. Despite the negative effects of the PDA-modified IEM, the SAC slightly increased when the IEM was simultaneously used with a PDA-modified electrode in the MCDI. Although there is no evidence for an increased SAC when using both PDA-modified electrode and IEM, there appears to be a synergetic effect where the dissolved salt ions are transported faster and/or in higher quantity between similar hydrophilic materials.

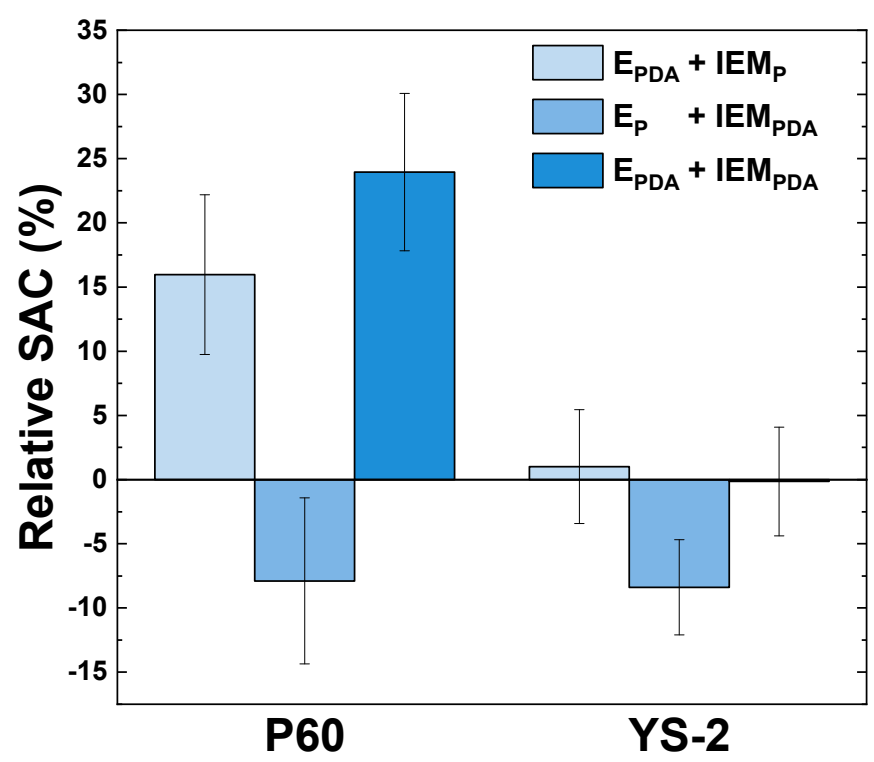

Figure 4. Relative salt adsorption capacity (SAC) in MCDI with three combinations of electrode and ion-exchange membrane (IEM); PDA-modified electrode and pristine IEM (EPDA + IEMP), pristine electrode and PDA-modified IEM (EP + IEMPDA), and PDA-modified electrode and IEM (EPDA + IEMPDA). Relative SAC was calculated by SAC at each combination divided from SAC at MCDI with pristine electrode and IEM. 
Table 3. Comparison of salt adsorption capacity (SAC) for three MCDI configurations.

\begin{tabular}{|c|c|c|c|}
\hline \multirow{2}{*}{ Activated Carbon Electrode } & \multicolumn{3}{|c|}{ Salt Adsorption Capacity (mg g $\mathrm{g}^{-1}$ ) } \\
\hline & $E_{P D A}+$ IEM $_{P}{ }^{1}$ & $E_{P}+I_{P M_{P D A}}{ }^{2}$ & $\mathrm{E}_{\mathrm{PDA}}+\mathrm{IEM}_{\mathrm{PDA}}{ }^{3}$ \\
\hline P60 & $12.9 \pm 0.4$ & $10.2 \pm 0.6$ & $13.8 \pm 0.2$ \\
\hline YS-2 & $13.2 \pm 0.8$ & $12.0 \pm 0.4$ & $13.0 \pm 0.7$ \\
\hline
\end{tabular}

${ }_{1}^{1} \overline{\text { MCDI with PDA-modified electrode and pristine IEM. }{ }^{2} \text { MCDI with pristine electrode and PDA-modified IEM. }}$

${ }^{3}$ MCDI with PDA-modified electrode and PDA-modified IEM.

To evaluate the effects of hydrophilic electrodes on desalination performance from the thermodynamic and kinetic points of view, a CDI Ragone plot was drawn, as shown in Figure 5. A shift in to the right means an improvement in the SAC and in the upward direction means a fast rate of salt adsorption (i.e., ASAR) [35]. As seen in Figure 5, YS-2 values (blue points) were positioned in a higher region, indicating better kinetics than P60 (black points) both before and after the PDA modification. After PDA modification, each plot shifted higher and to the right, indicating a higher and faster desalination performance. The improvement in SAC with the P60 electrode was larger than that with the YS-2 electrode, which is consistent with the larger increase in capacity (Figure 4). The results in Figures 4 and 5 support the theory that the use of hydrophilic electrodes could improve the desalination performance of MCDI.

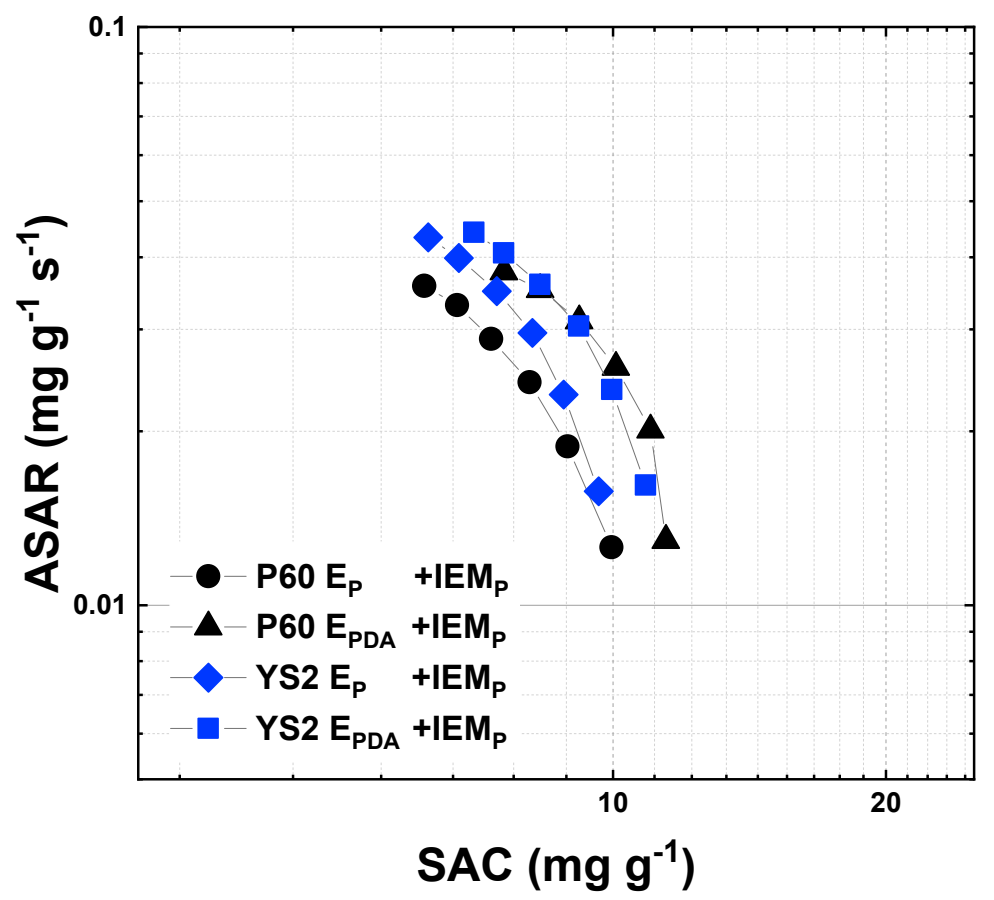

Figure 5. Capacitive deionization (CDI) ragone plot using pristine and PDA-modified P60 and YS-2 electrodes.

\section{Conclusions}

This study investigated the effect of the hydrophilicity in activated carbon electrodes on the desalination performance in MCDI. Our experiments employed P60 and YS-2 activated carbons, which have similar specific surface areas, but different hydrophilicities due to the $\mathrm{C}-\mathrm{N}$ or $\mathrm{C}=\mathrm{N}$ bonding. The results demonstrated that hydrophilic YS-2 electrode have larger SAC, indicating a positive effect of hydrophilicity on the desalination performance. After PDA modification to enhance the hydrophilicity of the electrode and/or IEM, the SAC of the P60 electrode effectively increased, resulting from a dramatically improved hydrophilicity. Conversely, PDA-modified IEM reduced the desalination performance in the MCDI by inhibiting ion transportation by acting as an insulator without changing the hydrophilicity. These results provide the effects of hydrophilicity of activated carbon electrodes 
on the desalination performance in MCDI and require further comparable study on the effects of hydrophilic electrode when treating high-salinity water or using high electric field and so on.

Supplementary Materials: The following are available online at http://www.mdpi.com/2076-3417/9/23/5055/s1, Figure S1: Salt adsorption capacity (SAC) of P60 and YS-2 electrodes in CDI, Figure S2: Contact angle image of ion-exchange membrane before/after polydopamine (PDA) modification, Figure S3: Salt adsorption capacity of PDA-modified P60 electrode and YS-2 electrode.

Author Contributions: Conceptualization, data acquisition and interpretation, and writing-original draft preparation and editing, K.J.; conceptualization, data interpretation, and writing-review and editing, Y.B.; writing-review, C.L.; supervision, writing-review, J.Y.

Funding: This work was supported by the Technology Innovation Program (10082572, Development of Low Energy Desalination Water Treatment Engineering Package System for Industrial Recycle Water Production) funded by the Ministry of Trade, Industry, and Energy (MOTIE, Korea), by the National Research Foundation of Korea (NRF) grant funded by the Ministry of Science, ICT and Future Planning (NRF-2018R1C1B5086300) and by the Sungshin Women's University Research Grant of 2018-2-85-003.

Conflicts of Interest: The authors declare no conflict of interest.

\section{References}

1. Kim, T.; Yoon, J. Relationship between capacitance of activated carbon composite electrodes measured at a low electrolyte concentration and their desalination performance in capacitive deionization. J. Electroanal. Chem. 2013, 704, 169-174. [CrossRef]

2. Han, L.; Karthikeyan, K.G.; Anderson, M.A.; Gregory, K.B. Exploring the impact of pore size distribution on the performance of carbon electrodes for capacitive deionization. J. Colloid Interface Sci. 2014, 430, $93-99$. [CrossRef] [PubMed]

3. Feng, C.; Chen, Y.A.; Yu, C.P.; Hou, C.H. Highly porous activated carbon with multi-channeled structure derived from loofa sponge as a capacitive electrode material for the deionization of brackish water. Chemosphere 2018, 208, 285-293. [CrossRef] [PubMed]

4. Tsouris, C.; Mayes, R.; Kiggans, J.; Sharma, K.; Yiacoumi, S.; DePaoli, D.; Dai, S. Mesoporous carbon for capacitive deionization of saline water. Environ. Sci. Technol. 2011, 45, 10243-10249. [CrossRef] [PubMed]

5. Zou, L.; Li, L.; Song, H.; Morris, G. Using mesoporous carbon electrodes for brackish water desalination. Water Res. 2008, 42, 2340-2348. [CrossRef]

6. Ahn, H.-J.; Lee, J.-H.; Jeong, Y.; Lee, J.-H.; Chi, C.-S.; Oh, H.-J. Nanostructured carbon cloth electrode for desalination from aqueous solutions. Mater. Sci. Eng. A 2007, 449, 841-845. [CrossRef]

7. Liu, F.; Wagterveld, R.M.; Gebben, B.; Otto, M.J.; Biesheuvel, P.M.; Hamelers, H.V.M. Carbon nanotube yarns as strong flexible conductive capacitive electrodes. Colloid Interface Sci. Commun. 2014, 3, 9-12. [CrossRef]

8. Lee, Y.H.; An, K.H.; Lee, J.Y.; Lim, S.C. Carbon Nanotube-Based supercapacitors. In Encyclopedia of Nanoscience and Nanotechnology; Nalwa, H.S., Ed.; American Scientific Publishers: Valencia, CA, USA, 2004; Volume 1, pp. 625-634.

9. Hu, W.; Xie, F.; Li, Y.; Wu, Z.; Tian, K.; Wang, M.; Pan, L.; Li, L. Hierarchically Porous Carbon Derived from PolyHIPE for Supercapacitor and Deionization Applications. Langmuir: ACS J. Surfaces Colloids 2017, 33, 13364-13375. [CrossRef]

10. Li, H.; Zou, L.; Pan, L.; Sun, Z. Novel graphene-like electrodes for capacitive deionization. Environ. Sci. Technol. 2010, 44, 8692-8697. [CrossRef]

11. Li, H.; Pan, L.; Lu, T.; Zhan, Y.; Nie, C.; Sun, Z. A comparative study on electrosorptive behavior of carbon nanotubes and graphene for capacitive deionization. J. Electroanal. Chem. 2011, 653, 40-44. [CrossRef]

12. Noonan, O.; Liu, Y.; Huang, X.; Yu, C. Layered Graphene/Mesoporous Carbon Heterostructures with Improved Mesopore Accessibility for High Performance Capacitive Deionization. J. Mater. Chem. A 2018, 6, 14272-14280. [CrossRef]

13. Wimalasiri, Y.; Zou, L. Carbon nanotube/graphene composite for enhanced capacitive deionization performance. Carbon 2013, 59, 464-471. [CrossRef]

14. Rivera-Munoz, E.M.; Huirache-Acuna, R. Sol gel-derived SBA-16 mesoporous material. Int. J. Mol. Sci. 2010, 11, 3069-3086. [CrossRef] [PubMed] 
15. Porada, S.; Borchardt, L.; Oschatz, M.; Bryjak, M.; Atchison, J.S.; Keesman, K.J.; Kaskel, S.; Biesheuvel, P.M.; Presser, V. Direct prediction of the desalination performance of porous carbon electrodes for capacitive deionization. Energy Environ. Sci. 2013, 6, 3700. [CrossRef]

16. Yang, S.J.; Kim, T.; Lee, K.; Kim, Y.S.; Yoon, J.; Park, C.R. Solvent evaporation mediated preparation of hierarchically porous metal organic framework-derived carbon with controllable and accessible large-scale porosity. Carbon 2014, 71, 294-302. [CrossRef]

17. Yang, Z.-Y.; Jin, L.-J.; Lu, G.-Q.; Xiao, Q.-Q.; Zhang, Y.-X.; Jing, L.; Zhang, X.-X.; Yan, Y.-M.; Sun, K.-N. Sponge-Templated Preparation of High Surface Area Graphene with Ultrahigh Capacitive Deionization Performance. Adv. Funct. Mater. 2014, 24, 3917-3925. [CrossRef]

18. Lee, J.-B.; Park, K.-K.; Eum, H.-M.; Lee, C.-W. Desalination of a thermal power plant wastewater by membrane capacitive deionization. Desalination 2006, 196, 125-134. [CrossRef]

19. Li, H.; Zou, L. Ion-exchange membrane capacitive deionization: A new strategy for brackish water desalination. Desalination 2011, 275, 62-66. [CrossRef]

20. Jain, A.; Kim, J.; Owoseni, O.M.; Weathers, C.; Cana, D.; Zuo, K.; Walker, W.S.; Li, Q.; Verduzco, R. Aqueous-Processed, High-Capacity Electrodes for Membrane Capacitive Deionization. Environ. Sci. Technol. 2018, 52, 5859-5867. [CrossRef]

21. Kim, Y.-J.; Choi, J.-H. Enhanced desalination efficiency in capacitive deionization with an ion-selective membrane. Sep. Purif. Technol. 2010, 71, 70-75. [CrossRef]

22. Biesheuvel, P.M.; Zhao, R.; Porada, S.; van der Wal, A. Theory of membrane capacitive deionization including the effect of the electrode pore space. J. Colloid Interface Sci. 2011, 360, 239-248. [CrossRef] [PubMed]

23. Zhao, R.; Biesheuvel, P.M.; Miedema, H.; Bruning, H.; van der Wal, A. Charge Efficiency: A Functional Tool to Probe the Double-Layer Structure Inside of Porous Electrodes and Application in the Modeling of Capacitive Deionization. J. Phys. Chem. Lett. 2009, 1, 205-210. [CrossRef]

24. Andelman, M.D.; Walker, G.S. Charge Barrier Flow-Through Capacitor. US6709560B2, 23 March 2004.

25. Suss, M.E.; Porada, S.; Sun, X.; Biesheuvel, P.M.; Yoon, J.; Presser, V. Water desalination via capacitive deionization: What is it and what can we expect from it? Energy Environ. Sci. 2015, 8, 2296-2319. [CrossRef]

26. Leonard, K.C.; Genthe, J.R.; Sanfilippo, J.L.; Zeltner, W.A.; Anderson, M.A. Synthesis and characterization of asymmetric electrochemical capacitive deionization materials using nanoporous silicon dioxide and magnesium doped aluminum oxide. Electrochim. Acta 2009, 54, 5286-5291. [CrossRef]

27. Myint, M.T.Z.; Al-Harthi, S.H.; Dutta, J. Brackish water desalination by capacitive deionization using zinc oxide micro/nanostructures grafted on activated carbon cloth electrodes. Desalination 2014, 344, $236-242$. [CrossRef]

28. Wu, T.; Wang, G.; Zhan, F.; Dong, Q.; Ren, Q.; Wang, J.; Qiu, J. Surface-treated carbon electrodes with modified potential of zero charge for capacitive deionization. Water Res. 2016, 93, 30-37. [CrossRef]

29. Kim, C.; Lee, J.; Kim, S.; Yoon, J. $\mathrm{TiO}_{2}$ sol-gel spray method for carbon electrode fabrication to enhance desalination efficiency of capacitive deionization. Desalination 2014, 342, 70-74. [CrossRef]

30. Xie, Z.; Cheng, J.; Yan, J.; Cai, W.; Nie, P.; Chan, H.T.H.; Liu, J. Polydopamine Modified Activated Carbon for Capacitive Desalination. J. Electrochem. Soc. 2017, 164, A2636-A2643. [CrossRef]

31. Baek, Y.; Freeman, B.D.; Zydney, A.L.; Yoon, J. A Facile Surface Modification for Antifouling Reverse Osmosis Membranes Using Polydopamine under UV Irradiation. Ind. Eng. Chem. Res. 2017, 56, 5756-5760. [CrossRef]

32. Lee, H.; Dellatore, S.M.; Miller, W.M.; Messersmith, P.B. Mussel-inspired surface chemistry for multifunctional coatings. Science 2007, 318, 426-430. [CrossRef]

33. Kang, J.; Kim, T.; Jo, K.; Yoon, J. Comparison of salt adsorption capacity and energy consumption between constant current and constant voltage operation in capacitive deionization. Desalination 2014, 352, 52-57. [CrossRef]

34. Yoon, H.; Jo, K.; Kim, K.J.; Yoon, J. Effects of characteristics of cation exchange membrane on desalination performance of membrane capacitive deionization. Desalination 2019, 458, 116-121. [CrossRef]

35. Kim, T.; Yoon, J. CDI ragone plot as a functional tool to evaluate desalination performance in capacitive deionization. RSC Adv. 2015, 5, 1456-1461. [CrossRef]

36. Przepiórski, J.; Skrodzewicz, M.; Morawski, A.W. High temperature ammonia treatment of activated carbon for enhancement of CO2 adsorption. Appl. Surf. Sci. 2004, 225, 235-242. [CrossRef]

37. Xie, Z.; Guan, W.; Ji, F.; Song, Z.; Zhao, Y. Production of Biologically Activated Carbon from Orange Peel and Landfill Leachate Subsequent Treatment Technology. J. Chem. 2014, 2014, 1-9. [CrossRef] 
38. Xiao, K.; Ding, L.X.; Liu, G.; Chen, H.; Wang, S.; Wang, H. Freestanding, Hydrophilic Nitrogen-Doped Carbon Foams for Highly Compressible All Solid-State Supercapacitors. Adv. Mater. 2016, 28, 5997-6002. [CrossRef]

39. Altman, D.G. Practical Statistics for Medical Research; Taylor \& Francis: Oxfordshire, UK, 1990.

40. Ma, D.; Cai, Y.; Wang, Y.; Xu, S.; Wang, J.; Khan, M.U. Grafting the Charged Functional Groups on Carbon Nanotubes for Improving the Efficiency and Stability of Capacitive Deionization Process. ACS Appl. Mater. Interfaces 2019, 11, 17617-17628. [CrossRef]

41. Kang, D.H.; Jo, H.; Jung, M.J.; Kim, K.L.; Lee, Y.S. Anatase $\mathrm{TiO}_{2}$-doped activated carbon fibers prepared by ultrasonication and their capacitive deionization characteristics. Carbon Lett. 2018, 27, 64-71.

42. Khan, Z.U.; Yan, T.; Shi, L.; Zhang, D. Improved capacitive deionization by using 3D intercalated graphene sheet-sphere nanocomposite architectures. Environ. Sci.: Nano 2018, 5, 980-991. [CrossRef]

43. Wei, K.; Zhang, Y.; Han, W.; Li, J.; Sun, X.; Shen, J.; Wang, L. A novel capacitive electrode based on TiO $2-\mathrm{NTs}^{2}$ array with carbon embedded for water deionization: Fabrication, characterization and application study. Desalination 2017, 420, 70-78. [CrossRef]

44. Liu, P.; Wang, H.; Yan, T.; Zhang, J.; Shi, L.; Zhang, D. Grafting sulfonic and amine functional groups on 3D graphene for improved capacitive deionization. J. Mater. Chem. A 2016, 4, 5303-5313. [CrossRef]

(C) 2019 by the authors. Licensee MDPI, Basel, Switzerland. This article is an open access article distributed under the terms and conditions of the Creative Commons Attribution (CC BY) license (http://creativecommons.org/licenses/by/4.0/). 